\title{
APLIKASI TEKNIK FUZZY DELPHI TERHADAP KEPERLUAN ELEMEN TEKNOLOGI SEBAGAI WADAH DALAM PEMBELAJARAN BERASASKAN PEMIKIRAN REKA BENTUK
}

\section{(APPLICATION OF FUZZY DELPHI METHOD AS A VITAL ELEMENT IN TECHNOLOGY AS A TOOL IN DESIGN THINKING BASED LEARNING)}

\author{
Nurulrabihah Mat Noh ${ }^{*}$, Saedah Siraj², Siti Hajar Halili³, \\ Mohd Ridhuan Mohd Jamil ${ }^{4}$ and Zaharah Husin ${ }^{3}$
}

${ }^{1}$ Unit Latihan dalam Perkhidmatan, Institut Pendidikan Guru Kampus Bahasa Melayu, Lingkungan Budi, 59100 Kuala Lumpur, Malaysia

${ }^{2}$ Faculty of Human Development, Universiti Perguruan Sultan Idris, 35900

Tanjong Malim, Perak, Malaysia

${ }^{3}$ Faculty of Education, Universiti Malaya, Jalan Universiti, 50603 Kuala Lumpur, Malaysia

${ }^{4}$ Centre of Research and Innovation, Politeknik Nilai, Kompleks Pendidikan Nilai, Bandar Enstek, 71760 Labu, Negeri Sembilan, Malaysia

*Corresponding author: nurulrabihah@ipgkbm.edu.my

Publication date: 24 December 2019

To cite this article: Nurulrabihah Mat Noh, Saedah Siraj, Siti Hajar Halili, Mohd Ridhuan Mohd Jamil, \& Zaharah Husin. (2019). Aplikasi teknik Fuzzy Delphi terhadap keperluan elemen teknologi sebagai wadah dalam pembelajaran berasaskan pemikiran reka bentuk. Asia Pacific Journal of Educators and Education, 34, 129-151. https://doi.org/10.21315/ apjee2019.34.7

To link to this article: https://doi.org/10.21315/apjee2019.34.7

\begin{abstract}
As technology becomes ubiquitous in society, there is increasing momentum to incorporate it into education. Therefore, the purpose of this study is to find out the elements needed in integrating technology as a tool for design thinking-based learning. This study is a quantitative study with Fuzzy Delphi method. The data was gathered using questionnaire. Verification is done by 18 experts in the field of education, educational technology and design thinking. The study found that expert consensus on all element is more than $75 \%$ with threshold value $(d) \leq 0.2$. This suggests that these eight elements are needed in integrating technology as a tool for design thinking-based learning.
\end{abstract}


Keywords: technology, design thinking, education, ICT, Fuzzy Delphi

\begin{abstract}
Abstrak: Apabila teknologi menjadi penting dalam kehidupan masyarakat, terdapat gesaan untuk mengintegrasikan teknologi ke dalam pendidikan. Justeru kajian ini bertujuan untuk melihat elemen-elemen yang diperlukan dalam mengintegrasikan teknologi sebagai wadah dalam pembelajaran berasaskan pemikiran reka bentuk. Kajian yang dijalankan ini merupakan satu kajian kuantitatif dengan teknik Fuzzy Delphi. Pendekatan yang digunakan untuk mengumpul data kajian adalah menggunakan instrumen soal selidik. Bilangan pakar yang terlibat adalah seramai 18 orang dalam bidang pendidikan, teknologi pendidikan dan pemikiran reka bentuk. Hasil dapatan kajian menunjukkan bahawa kelapan-lapan elemen diterima oleh pakar dengan peratus konsensus melebihi $75 \%$ dengan nilai ambang $(d) \leq 0.2$. Ini menunjukkan bahawa kelapan-lapan elemen ini diperlukan dalam mengintegrasikan teknologi sebagai wadah dalam pembelajaran berasaskan pemikiran reka bentuk.
\end{abstract}

Kata Kunci: teknologi, pemikiran reka bentuk, pendidikan, ICT, Fuzzy Delphi

\title{
PENGENALAN
}

Revolusi Industri 4.0 memerlukan negara melakukan perubahan seiring dengan transformasi digital untuk kekal berdaya saing. Walaupun perkembangan pesat teknologi mengubah cara kita berfikir, bekerja, bermain dan berhubung antara satu sama lain tetapi menurut Robinson (2011), banyak di antara kita masih berada di zon selesa yang masih mengamalkan cara pemikiran lama. Begitu juga senario yang berlaku dalam dunia pendidikan di mana menurut Dougherty (2015), dunia pendidikan masih tidak menyedari sepenuhnya bagaimana teknologi benar-benar mempengaruhi pembelajaran seharian.

Prensky (2010) menyatakan kebimbangannya dengan mendesak para guru mempersiapkan murid bukan sahaja untuk menghadapi dunia masa kini tetapi juga dunia masa depan, di mana pada saat itu penggunaan teknologi adalah satu trillion lebih pesat daripada teknologi pada hari ini. Melihat daripada jangkaan fenomena ini, guru perlu mempersiapkan diri dengan kemahiran teknologi yang diperlukan. Lebih membimbangkan bila dapatan kajian yang dijalankan oleh Collins dan Halverson (2009) menunjukkan bahawa teknologi telah menjadikan hidup para guru lebih sukar. Menurut Collins dan Halverson (2009) lagi, masalah ini berpunca daripada kemahiran yang dimiliki oleh para guru tidak mencukupi dalam mengintegrasikan teknologi dalam pendidikan.

Sejajar dengan itu, Hartley (2014) telah menjalankan kajian dalam meneroka halangan mengintegrasikan teknologi dalam kalangan guru sekolah rendah. Hasil 
kajian mendapati empat halangan utama iaitu kekurangan latihan dan sokongan teknikal, kekurangan prioriti dan sokongan pentadbir, kekurangan sumber dan kemudahan serta beban kerja guru (Hartley, 2014). Kajian yang dijalankan oleh Crane (2005) pula mendapati persepsi guru, peranan dan tanggungjawab terhadap integrasi teknologi oleh sekolah yang mempunyai program teknologi intensif adalah positif. Kajian ini mengetengahkan tiga tema penting terhadap integrasi teknologi dalam pendidikan iaitu halangan kepada integrasi, kepentingan latihan teknologi dan persekitaran pembelajaran. Kesimpulannya, dapatan kedua-dua kajian ini jelas menunjukkan bahawa komponen penting dalam kejayaan integrasi teknologi dalam pendidikan adalah penerapan kemahiran teknologi kepada guruguru dalam kursus pembangunan profesionalisme.

Aspek pembelajaran abad ke-21 termasuklah menyediakan pembelajaran kendiri, memupuk persekitaran bilik darjah kolaboratif dan mempromosikan literasi teknologi maklumat dan komunikasi (ICT) (Chai, Deng, Tsai, Koh, \& Tsai, 2015). Justeru teknologi dalam pendidikan dapat memberikan impak positif kepada pembangunan kemahiran abad ke-21 murid seperti meningkatkan motivasi, pembelajaran kolaboratif, pemikiran kritis dan kreatif (Koehler \& Mishra, 2005; Sara Jolly, 2017). Sejajar dengan itu, Claro et al. (2012) mencadangkan supaya pakar akademik membangunkan kemahiran berkaitan ICT, di mana kurikulum perlu direka untuk meningkatkan penggunaan ICT di sekolah dengan orientasi pedagogi yang menggalakkan penggunaan secara lazim dan kreatif. Melihat kepada cadangan yang dinyatakan, kajian ini akan mengetengahkan persoalan kajian seperti berikut:

1. Berdasarkan pandangan pakar, apakah elemen yang diperlukan dalam mengintegrasikan teknologi sebagai wadah dalam pembelajaran berasaskan pemikiran reka bentuk?

2. Berdasarkan pandangan pakar, apakah kedudukan elemen yang diperlukan dalam mengintegrasikan teknologi sebagai wadah dalam pembelajaran berasaskan pemikiran reka bentuk?

\section{SOROTAN LITERATUR}

Pengintegrasian teknologi dalam bilik darjah tidak boleh dikesampingkan oleh para guru. Hujah ini bersandarkan perspektif Trilling dan Fadel (2009) dan Dougherty (2015) yang menyatakan bahawa penggunaan teknologi adalah salah satu wadah kepada guru-guru memperoleh amalan pemikiran yang lebih inovatif, kreatif dan seterusnya mengintegrasikan amalan pemikiran reka bentuk ke dalam reka bentuk pengajaran dan pembelajaran. Sejajar dengan itu, para guru dapat 
meningkatkan tahap inovasi, kreativiti dan pemikiran reka bentuk bermula dengan menggabungkan penggunaan teknologi dalam pengajaran dan pembelajaran mereka (Boss, 2012).

Melihat teknologi semata-mata sebagai beban tugas guru dari segi penyediaan material dan mengakses bahan adalah pandangan yang tidak berasas. Ini kerana penggunaan teknologi dalam abad ke-21 lebih luas dan lebih eksklusif, di mana penguasaan teknologi murid lebih daripada kemahiran teknologi guru dan ibu bapa, dan pada tahap ini peranan guru lebih kepada menjadi fasilitator yang berperanan membimbing murid untuk mengaplikasikan teknologi dalam pembelajaran yang lebih kompleks dan kreatif (Trilling \& Fadel, 2009). Ini menunjukkan pengintegrasian teknologi pada masa kini lebih berpusatkan kreativiti, kerjasama dan pembelajaran berasaskan projek. Justeru untuk menerapkan pengintegrasian teknologi dengan cara ini, sokongan perlu diberikan kepada guru untuk mereka bentuk pembelajaran kreatif yang baik. Oleh itu, pembelajaran berasaskan pemikiran reka bentuk boleh memberi panduan dalam menyokong pandangan mengenai pengintegrasian teknologi ini.

Pada dasarnya, pemikiran reka bentuk didefinisikan sebagai metodologi penyelesaian masalah dengan pembinaan strategi secara inovatif untuk disesuaikan dengan keperluan manusia yang boleh dilaksanakan dengan teknologi (Brown, 2008). Mutakhir ini perbincangan mengenai pemikiran reka bentuk dan potensinya dalam pengajaran dan pembelajaran semakin rancak diperdebatkan (Norton \& Hathaway, 2015). Antaranya keupayaan pemikiran reka bentuk yang diletakkan sebagai lensa teori dalam pendidikan (Kirschner, 2015; Mishra \& Koehler, 2006; Norton \& Hathaway, 2015), dan metode penyelesaian masalah kompleks (Buchanan, 2001; Kelley \& Van Patter, 2005). Justifikasi model ini dipilih sebagai landasan kajian adalah kerana model ini mengetengahkan penggunaan teknologi dalam pemikiran reka bentuk. Ini kerana teknologi yang baik berupaya membantu proses pemikiran reka bentuk seterusnya meningkatkan tahap inovasi dan kreativiti (Buchanan, 2001). Pendek kata, teknologi adalah wadah terpenting dalam pengintegrasian pembelajaran berasaskan pemikiran reka bentuk. Penggunaan teknologi yang berkesan hanya boleh direalisasikan oleh guru yang dilengkapi dengan kemahiran ini. Justeru melihat kepada keperluan yang dinyatakan, adalah penting untuk mengetahui elemen-elemen yang diperlukan dalam domain teknologi sebagai wadah dalam pembelajaran berasaskan reka bentuk. 


\section{Model Bimbingan Pelajar kepada Pemikiran Reka Bentuk Abad Ke-21}

Model ini diasaskan oleh Koh, Chai, Wong dan Hong (2015) yang memberi garis panduan yang jelas bagaimana mengintegrasikan teknologi dalam pembelajaran berasaskan pemikiran reka bentuk melalui lima episod yang telah diketengahkan. Koh et al. (2015) menegaskan bahawa pembelajaran berasaskan pemikiran reka bentuk melibatkan beberapa episod penciptaan yang bermula daripada fasa awal masalah mereka bentuk hingga kepada penyelesaian yang konkrit. Justifikasi pengkaji memilih model ini sebagai landasan kajian adalah kerana model ini mengetengahkan penggunaan teknologi dalam pemikiran reka bentuk. Hal ini bertepatan dengan objektif kajian ini yang ingin melihat pandangan pakar mengenai elemen-elemen yang diperlukan dalam mengintegrasikan teknologi sebagai wadah dalam pembelajaran berasaskan pemikiran reka bentuk.

Uniknya model ini adalah kerana dalam setiap episod telah disediakan soalan panduan yang dapat mencetus pemikiran murid untuk merangka proses mereka bentuk. Episod ini terbahagi kepada lima bahagian iaitu kognitif, sosial budaya, teknikal, produktiviti dan meta kognitif. Episod pertama iaitu episod kognitif adalah bertujuan untuk membantu murid menyelesaikan masalah yang dihadapi dengan mempertimbangkan apa yang mereka ketahui dan bagaimana pengetahuan ini dapat membantu mereka menyelesaikan masalah. Justeru beberapa soalan telah disenaraikan yang bertujuan untuk menggalakkan murid mempertimbangkan soalan-soalan yang perlu ditanya mengenai masalah, maklumat yang mereka cari serta penyelesaian yang mungkin boleh dicuba (Koh et al., 2015). Manakala dalam episod sosial budaya murid perlu memahami konteks sosial budaya sesuatu masyarakat sebelum melakukan aktiviti empati. Contohnya, sebagai rakyat Malaysia yang hidup berbilang kaum, murid seharusnya mengetahui sensitiviti sesuatu agama sebelum melakukan aktiviti empati. Hal ini termasuklah apa yang boleh dimakan dan tidak boleh dimakan dalam sesuatu kepercayaan agama seperti penganut Hindu tidak boleh makan daging lembu manakala penganut Islam tidak boleh makan daging khinzir. Di sini murid perlu peka terhadap sensitiviti sesuatu kaum supaya tidak mengemukakan soalan yang boleh mencetuskan ketegangan kepada kumpulan sasar. Hal ini bertitik tolak daripada peranan pereka yang lebih mementingkan penglibatan sosial dan proses mereka bentuk daripada menyelesaikan masalah itu sendiri (Taboada \& Coombs, 2013).

Episod seterusnya adalah episod teknikal yang memberi fokus kepada penggunaan teknologi. Episod ini akan membimbing murid menguasai kemahiran teknologi yang menghubungkan dunia melebihi sumber yang sedia ada seperti guru dan buku teks. Soalan pertama yang dikemukakan oleh Koh et al. (2015) dalam episod ini adalah, pada siapa dan bagaimanakah sumber maklumat yang boleh murid 
hubungkan melebihi apa yang diakses pada masa ini? Ini meliputi penggunaan teknologi yang dimanfaatkan oleh murid untuk berinteraksi terus dengan pakar atau ahli komuniti tempatan atau global. Umum mengetahui teknologi tanpa sempadan memudahkan murid berkomunikasi dengan sesiapa sahaja termasuk juga pakar antarabangsa. Ini secara langsung memberi peluang kepada murid bersuara dan membuat pilihan dengan penggunaan teknologi (Zhao, 2012). Elemen pengetahuan ini dapat menambahkan metakognisi murid serta menjadi satu medium perkongsian dengan pemegang taruh dan ahli kumpulan yang terlibat dalam proses mereka bentuk (Koh et al., 2015).

Banyak kajian telah mendedahkan bagaimana penggunaan teknologi dapat meningkatkan tahap kreativiti, inovasi dan pemikiran reka bentuk (Dougherty, 2015; Trilling \& Fadel, 2009). Koh et al. (2015) dalam soalan bimbingan yang seterusnya, membolehkan murid mempertimbangkan teknologi yang boleh dieksploitasi untuk melakukan projek dengan lebih efisien. Ini termasuklah video, tutorial dan laman web pengajaran kendiri demi untuk mendapatkan pemahaman yang lebih mendalam sebelum sesuatu masalah diselesaikan. Hal ini bersangkut paut dengan teori yang dikemukakan oleh Dewey dan Dewey (1915), di mana murid menggunakan pengetahuan sedia ada dan pengetahuan semasa untuk membuat hubungan yang lebih mendalam terhadap pembelajaran mereka. Dengan mengekploitasi penggunaan teknologi membolehkan murid lebih berekplorasi dan membina pengalaman baharu. Oleh itu, penggunaan teknologi dalam pembelajaran berasaskan reka bentuk dapat menyokong teori konstruktivisme dalam meningkatkan tahap inovasi, kreativiti dan pemikiran reka bentuk (Marlowe \& Page, 1998). Dalam soalan ini juga murid perlu mempertimbangkan sumber teknologi yang sesuai untuk menyelesaikan tugas mereka. Cara ini dapat mendedahkan murid kepada pelbagai jenis teknologi yang ada melalui pengalaman pembelajaran dan seterusnya membantu meningkatkan tahap kreativiti, inovasi dan pemikiran reka bentuk (Collins \& Halverson, 2009).

Dalam episod ini juga, Koh et al. (2015) mencadangkan soalan yang menjurus kepada pertimbangan murid terhadap kebolehpercayaan data yang telah mereka perolehi. Ini kerana internet menawarkan pelbagai jenis maklumat yang sentiasa bertambah. Oleh itu murid perlu sedar setiap maklumat yang dipaparkan di dalam internet tidak semuanya betul dan murid perlu menilai kredibiliti dan kesahan maklumat yang diperoleh dalam talian sebelum digunakan sebagai rujukan (Baharuddin et al., 2003). Justeru Jayabalan (2009) telah menggariskan lima kemahiran yang perlu dimiliki untuk mendapatkan maklumat menerusi internet iaitu kemahiran menilai dari segi (1) ketepatan, (2) kewibawaan, (3) objektif, (4) kekinian dan (5) liputan maklumat yang terdapat dalam Internet. 
Menurut Koh et al. (2015), dalam episod ini juga murid perlu mempertimbangkan bagaimana mereka dapat menyatakan pendapat dengan jelas dan mewakili pengetahuan yang mereka hasilkan sepanjang proses mereka bentuk dengan menggunakan komputer sebagai alat kognitif. Ini termasuklah penggunaan teknologi untuk menyokong dan memantau kerja pasukan seperti penggunaan e-mel dan aplikasi WhatsApp. Penggunaan teknologi ini merupakan salah satu medium perkongsian untuk meningkatkan komunikasi dengan ahli kumpulan dan juga pemegang taruh dalam proses mereka bentuk (Koh et al., 2015).

Dalam episod ini juga, murid diminta untuk mempertimbangkan beberapa elemen seperti bahasa, grafik dan multimedia. Dalam fasa ini, murid perlu mengeksploitasi teknologi untuk menganalisis maklumat dengan menggunakan perisian seperti pangkalan data atau Microsoft Excel. Murid juga dapat berkongsi maklumat atau dapatan yang diperoleh dengan menggunakan teknologi. Contohnya membuat persembahan multimedia, blog, audiosiar (podcast) dan lain-lain. Melalui proses ini, murid belajar mengeksploitasi dengan bijak seperti yang dijelaskan dalam rangka pembelajaran abad ke-21. Walau bagaimanapun harus diketahui bahawa aspek kritikal dalam penggunaan digital adalah kebolehan untuk merancang dengan efektif dan kebolehan memantau keberkesanan strategi yang digunakan untuk mencari dan menguruskan maklumat yang ada dalam talian (Greene, Yu, \& Copeland, 2014).

Episod produktiviti yang dikemukakan oleh Koh et al. (2015) bertujuan untuk melancarkan kecekapan dan keberkesanan proses kerja serta kemahiran abad ke-21 yang berkaitan dengan kebolehcapaian dan fleksibiliti. Manakala episod metakognitif bertujuan mendorong murid untuk mempertimbangkan bagaimana untuk menangani masalah sepanjang proses reka bentuk artifak, penyesuaian yang perlu dilakukan serta reaksi sosial dan emosi terhadap proses kerja mereka bentuk. Dalam episod ini, murid digalakkan untuk membuat penilaian dan mempertimbangkan bagaimana keupayaan diri dapat dipertingkatkan dan seterusnya membolehkan seseorang berjaya mencapai matlamat luaran dan dalaman seperti yang diterangkan dalam rangka pembelajaran abad ke-21. Rajah 1 menunjukkan model bimbingan pelajar kepada pemikiran reka bentuk abad ke-21. 


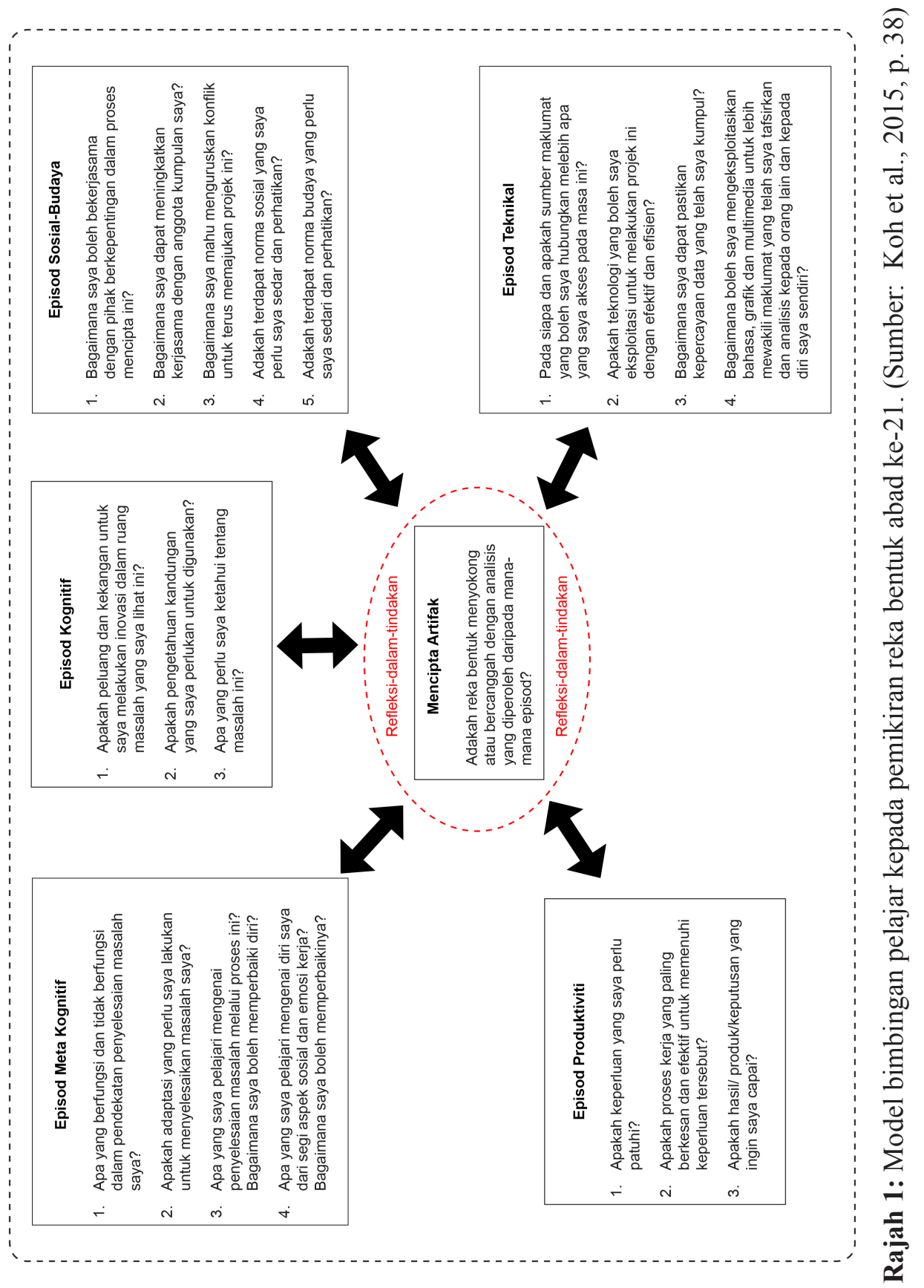




\section{METODOLOGI}

Kajian ini menggunakan teknik Fuzzy Delphi. Rasional pengkaji menggunakan teknik ini bersandarkan hujah Mohd Ridhuan, Saedah, Zaharah, Nurulrabihah dan Ahmad Ariffin (2017) yang mengatakan bahawa teknik Fuzzy Delphi mampu digunakan bagi mendapatkan konsensus pakar dalam sesuatu permasalahan. Justeru untuk menjawab persoalan kajian yang telah dinyatakan, pengkaji telah membangunkan soal selidik lima mata. Dalam soal selidik, para pakar bertindak menentukan elemen-elemen yang diperlukan dalam mengintegrasikan teknologi sebagai wadah dalam pembelajaran berasaskan pemikiran reka bentuk. Soal selidik ini diadaptasi daripada 21st Century Teaching and Learning Survey (Hixson, Ravitz, \& Whisman, 2012) yang mempunyai nilai kebolehpercayaan yang baik (standard Alpha $>0.90$, korelasi $>0.58$ ).

\section{Responden Pakar}

Menurut Ocampo, Ebisa, Ombe dan Geen Escoto (2018), bilangan pakar dalam kajian tidak perlu ramai kerana tidak terdapat hubungan yang kuat antara bilangan pakar dengan kualiti keputusan yang boleh dihasilkan daripada perbincangan kumpulan. Sejajar dengan itu pengkaji telah memilih seramai 18 orang pakar berdasarkan cadangan Adler dan Ziglio (1996) dan Jones dan Twiss (1978). Menurut Adler dan Ziglio (1996), bilangan pakar yang sesuai adalah antara 10 hingga 15 orang, jika sekiranya terdapat keseragaman yang tinggi dalam kalangan pakar yang dipilih. Manakala Jones dan Twiss (1978) pula mencadangkan bilangan pakar seramai 10-50 orang. Selain itu pakar yang dipilih perlu ada latar belakang atau pengalaman dalam bidang yang berkaitan dengan kajian yang dijalankan, pemilihan ini dapat menyokong pendapat mereka kepada keperluan kajian serta dapat menyemak semula penghakiman awal mereka untuk mencapai konsensus dalam kalangan pakar (Pill, 1971). Ini kerana menurut Saaty dan Özdemir (2014), menambah lebih ramai pakar yang tidak berpengalaman dapat melemahkan ketepatan keputusan. Pakar yang dipilih mestilah memenuhi kriteria berikut:

1. Berpengetahuan dalam bidang dikaji iaitu sekurang-kurangnya mempunyai Ijazah Sarjana dalam bidang pendidikan, teknologi pendidikan atau bidang berkaitan pemikiran reka bentuk.

2. Berpengalaman dalam bidang yang dikaji dan mempunyai pengalaman sekurang-kurangnya lima tahun dalam bidang berkaitan.

3. Dapat memberi komitmen sepenuhnya sehingga kajian selesai dijalankan.

4. Tidak mempunyai kepentingan peribadi untuk mengelakkan kajian yang berat sebelah. 
Jadual 1 menunjukkan profil pakar yang terlibat.

Jadual 1. Profil pakar yang terlibat.

\begin{tabular}{|c|c|c|c|}
\hline Pakar & Kelulusan & Kepakaran & Pengalaman \\
\hline $\mathrm{P} 1$ & Ijazah Sarjana & $\begin{array}{l}\text { Pakar pedagogi } \\
\text { Guru pakar di sekolah kebangsaan }\end{array}$ & 10 tahun \\
\hline $\mathrm{P} 2$ & Ijazah Sarjana & $\begin{array}{l}\text { Pakar pedagogi } \\
\text { Guru pakar di sekolah kebangsaan }\end{array}$ & 11 tahun \\
\hline P3 & Doktor Falsafah & $\begin{array}{l}\text { Pakar pedagogi } \\
\text { Pakar kurikulum } \\
\text { Pakar bahasa } \\
\text { Pensyarah cemerlang di Institut Pendidikan Guru } \\
\text { (IPG) }\end{array}$ & 26 tahun \\
\hline P4 & Doktor Falsafah & $\begin{array}{l}\text { Pakar pedagogi } \\
\text { Pakar kurikulum } \\
\text { Pakar bahasa } \\
\text { Munsyi Dewan Bahasa dan Pustaka (DBP) dan } \\
\text { pensyarah cemerlang di IPG }\end{array}$ & 24 tahun \\
\hline P5 & Ijazah Sarjana & $\begin{array}{l}\text { Pakar pemikiran reka bentuk } \\
\text { Perunding latihan kanan pemikiran reka bentuk } \\
\text { di Institut Tadbiran Awam Negara (INTAN) }\end{array}$ & 21 tahun \\
\hline P6 & Ijazah Sarjana & $\begin{array}{l}\text { Pakar pemikiran reka bentuk } \\
\text { Perunding latihan kanan pemikiran reka bentuk } \\
\text { di INTAN }\end{array}$ & 10 tahun \\
\hline $\mathrm{P} 7$ & Doktor Falsafah & $\begin{array}{l}\text { Pakar teknologi dan pendidikan } \\
\text { Pensyarah di Institut Aminuddin Baki }\end{array}$ & 20 tahun \\
\hline P8 & Ijazah Sarjana & $\begin{array}{l}\text { Pakar pedagogi } \\
\text { Guru pakar di sekolah kebangsaan }\end{array}$ & 16 tahun \\
\hline P9 & Doktor Falsafah & $\begin{array}{l}\text { Pakar kurikulum } \\
\text { Pakar metode kajian } \\
\text { Pensyarah di Universiti Awam }\end{array}$ & 25 tahun \\
\hline $\mathrm{P} 10$ & Doktor Falsafah & $\begin{array}{l}\text { Pakar kurikulum } \\
\text { Timbalan Dekan Ijazah Tinggi Universiti Awam }\end{array}$ & 29 tahun \\
\hline P11 & Ijazah Sarjana & $\begin{array}{l}\text { Pakar teknologi dan pendidikan } \\
\text { Penolong Pengarah di Bahagian Sumber dan } \\
\text { Teknologi Pendidikan }\end{array}$ & 10 tahun \\
\hline $\mathrm{P} 12$ & Ijazah Sarjana & $\begin{array}{l}\text { Pakar teknologi dan pendidikan } \\
\text { Juru latih utama Pembelajaran Teknologi } \\
\text { Maklumat dan Komunikasi (Information } \\
\text { Technology and Communication Learning, } \\
\text { ICTL) }\end{array}$ & 12 tahun \\
\hline
\end{tabular}


Jadual 1. (sambungan)

\begin{tabular}{|c|c|c|c|}
\hline Pakar & Kelulusan & Kepakaran & Pengalaman \\
\hline P13 & Ijazah Sarjana & $\begin{array}{l}\text { Pakar pedagogi } \\
\text { Guru pakar di sekolah kebangsaan }\end{array}$ & 14 tahun \\
\hline P14 & Doktor Falsafah & $\begin{array}{l}\text { Pakar pedagogi } \\
\text { Pakar kurikulum } \\
\text { Pensyarah cemerlang di IPG }\end{array}$ & 30 tahun \\
\hline P15 & Ijazah Sarjana & $\begin{array}{l}\text { Pakar teknologi dan pendidikan } \\
\text { Juru latih utama ICTL }\end{array}$ & 20 tahun \\
\hline P16 & Ijazah Sarjana & $\begin{array}{l}\text { Pakar teknologi dan pendidikan } \\
\text { Juru latih utama ICTL }\end{array}$ & 23 tahun \\
\hline P17 & Ijazah Sarjana & $\begin{array}{l}\text { Pakar pedagogi } \\
\text { Guru pakar di sekolah kebangsaan }\end{array}$ & 17 tahun \\
\hline P18 & Ijazah Sarjana & $\begin{array}{l}\text { Pakar teknologi dan pendidikan } \\
\text { Juru latih utama ICTL }\end{array}$ & 10 tahun \\
\hline
\end{tabular}

\section{Analisis Data}

Data yang diperoleh telah dianalisis menggunakan perisian Microsoft Excel mengikut langkah-langkah yang dicadangkan oleh Chang, Huang dan Lin (2000) dan Mohd Ridhuan et al. (2017). Langkah-langkah itu adalah seperti berikut:

Langkah 1: Andaikan bahawa pakar $K$ dijemput untuk menentukan kepentingan bagi kriteria penilaian terhadap pemboleh ubah yang akan diukur dengan menggunakan pemboleh ubah linguistik (Jadual 2).

Jadual 2. Skala pemboleh ubah linguistik lima mata

\begin{tabular}{lc}
\hline Pemboleh ubah linguistik & Skala fuzzy \\
\hline Sangat Tidak Setuju & $(0.0,0.0,0.2)$ \\
Tidak Setuju & $(0.0,0.2,0.4)$ \\
Sederhana Setuju & $(0.2,0.4,0.6)$ \\
Setuju & $(0.4,0.6,0.8)$ \\
Sangat Setuju & $(0.6,0.8,1.0)$ \\
\hline
\end{tabular}

Langkah 2: Menukarkan ke semua pemboleh ubah lingustik ke dalam penomboran segitiga fuzzy (triangular fuzzy number) seperti yang dicadangkan dalam Jadual 2. Andaikan nombor fuzzy adalah pemboleh ubah untuk setiap kriteria untuk pakar $k_{t h}$ untuk: 
Nurulrabihah Mat Noh et al.

$$
\widetilde{\mathrm{r}}_{\mathrm{ij}}=\frac{1}{\mathrm{~K}}\left[\widetilde{\mathrm{r}}_{\mathrm{ij}}^{1} \oplus \widetilde{\mathrm{r}}_{\mathrm{ij}}^{2} \oplus \ldots \oplus \widetilde{\mathrm{r}}_{\mathrm{ij}}^{\mathrm{K}}\right]_{i=1, \ldots, m j=1, \ldots, n, k=1, \ldots, K}
$$

dan

Langkah 3: Bagi setiap pakar, gunakan kaedah vertex untuk mengira jarak di antara $\tilde{\mathrm{r}}_{\mathrm{ij}}$ dan $\tilde{\mathrm{r}}_{\mathrm{ij}}$ (lihat Chen, 2000). Syarat yang perlu dipatuhi adalah nilai ambang d $(\mathrm{m}, \mathrm{n})$ yang diperoleh mestilah kurang atau sama dengan nilai 0.2 (Cheng \& Lin, 2002).

Jarak bagi dua nombor fuzzy atau lebih dikenali sebagai nilai ambang dikira menggunakan rumus:

$$
\mathrm{d}(m, n)=\sqrt{\frac{1}{3}\left[\left(m_{1}-n_{2}\right)^{2}+\left(m_{2}-n_{2}\right)^{2}+\left(m_{3}-n_{3}\right)^{2}\right]}
$$

Langkah 4: Pada langkah 3, pakar $m \times n$, jika peratusan mencapai konsensus kumpulan adalah lebih daripada 75\% (Chu \& Hwang, 2008; Murry \& Hammons, 2017), seterusnya pergi ke Langkah 5. Jika sebaliknya, pusingan kedua teknik Fuzzy Delphi perlu dilakukan.

Langkah 5: Agregat penilaian fuzzy dengan:

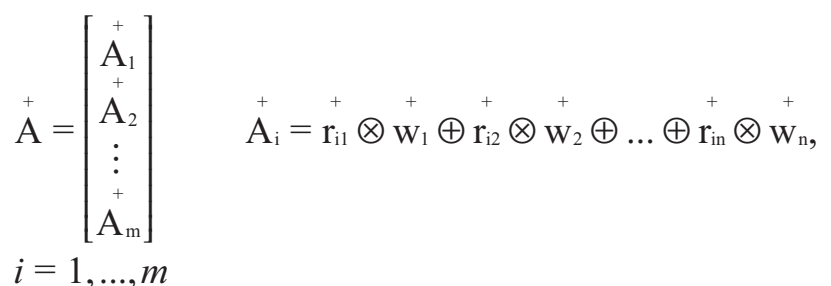

Langkah 6: Bagi setiap pilihan alternatif, penilaian fuzzy di defuzzication dengan rumus:

$$
a_{i}=\frac{1}{4}\left(a_{i 1}+2 a_{i 2}+a_{i 3}\right)
$$

Alternatif turutan pilihan ranking boleh ditentukan mengikut nilai $a_{i}$.

Bagi memastikan penerimaan konsensus pakar, syarat seterusnya harus dipatuhi di mana nilai $\alpha$-cut yang diperoleh mesti sama atau melebihi 0.5 (Bodjanova, 2006; Tang \& Wu, 2010). 


\section{DAPATAN KAJIAN}

\section{Konsensus Kumpulan}

Data telah disintesis daripada pengedaran soal selidik untuk mendapatkan konsensus kumpulan sebelum soalan kajian pertama dijawab. Dalam konteks teknik Fuzzy Delphi, kriteria yang digunakan untuk menilai konsensus kumpulan adalah berdasarkan syarat perjanjian iaitu peratusan kumpulan mesti melebihi 75\% (Chu \& Hwang, 2008; Murry \& Hammons, 2017). Sebelum mendapatkan konsensus kumpulan, nilai ambang telah dikira menggunakan rumus berikut:

$$
\mathrm{d}(m, n)=\sqrt{\frac{1}{3}\left[\left(m_{1}-n_{2}\right)^{2}+\left(m_{2}-n_{2}\right)^{2}+\left(m_{3}-n_{3}\right)^{2}\right]}
$$

Dalam konteks ini, syarat yang perlu dipatuhi adalah nilai ambang $d(m, n)$ yang diperoleh mestilah kurang atau sama dengan nilai 0.2 (Cheng \& Lin, 2002). Berdasarkan data analisis, nilai ambang $\mathrm{d}(m, n)$ untuk kelapan-lapan elemen adalah kurang daripada 0.2 dengan nilai peratus persetujuan melebihi $75 \%$ (Jadual 3). Oleh itu persoalan kajian pertama telah mencapai konsensus kumpulan.

\section{Proses Defuzzification bagi Analisis Soal Selidik: Elemen yang Diperlukan dalam Mengintegrasikan Teknologi sebagai Wadah dalam Pembelajaran Berasaskan Pemikiran Reka Bentuk}

Seperti yang telah diterangkan dalam metodologi kajian, proses defuzzification berfungsi untuk menentukan kedudukan sesuatu elemen berdasarkan kepada konsensus pakar. Proses ini dilakukan setelah pengkaji berjaya mendapatkan konsensus kumpulan. Jadual 3 menunjukkan hasil analisis berdasarkan konsensus pakar. Nilai defuzzification yang diterjemahkan dalam Jadual 3 juga turut mematuhi syarat seterusnya di mana nilai $\alpha$-cut yang diperoleh mesti sama atau melebihi 0.5 (Bodjanova, 2006; Tang \& Wu, 2010). Maka dengan ini semua elemen yang dibentangkan telah diterima oleh semua pakar. Secara tidak langsung, semua elemen yang dibentangkan ini juga telah menjawab soalan kajian pertama iaitu, "berdasarkan pandangan pakar apakah elemen yang diperlukan dalam mengintegrasikan teknologi sebagai wadah dalam pembelajaran berasaskan pemikiran reka bentuk?". 
Nurulrabihah Mat Noh et al.

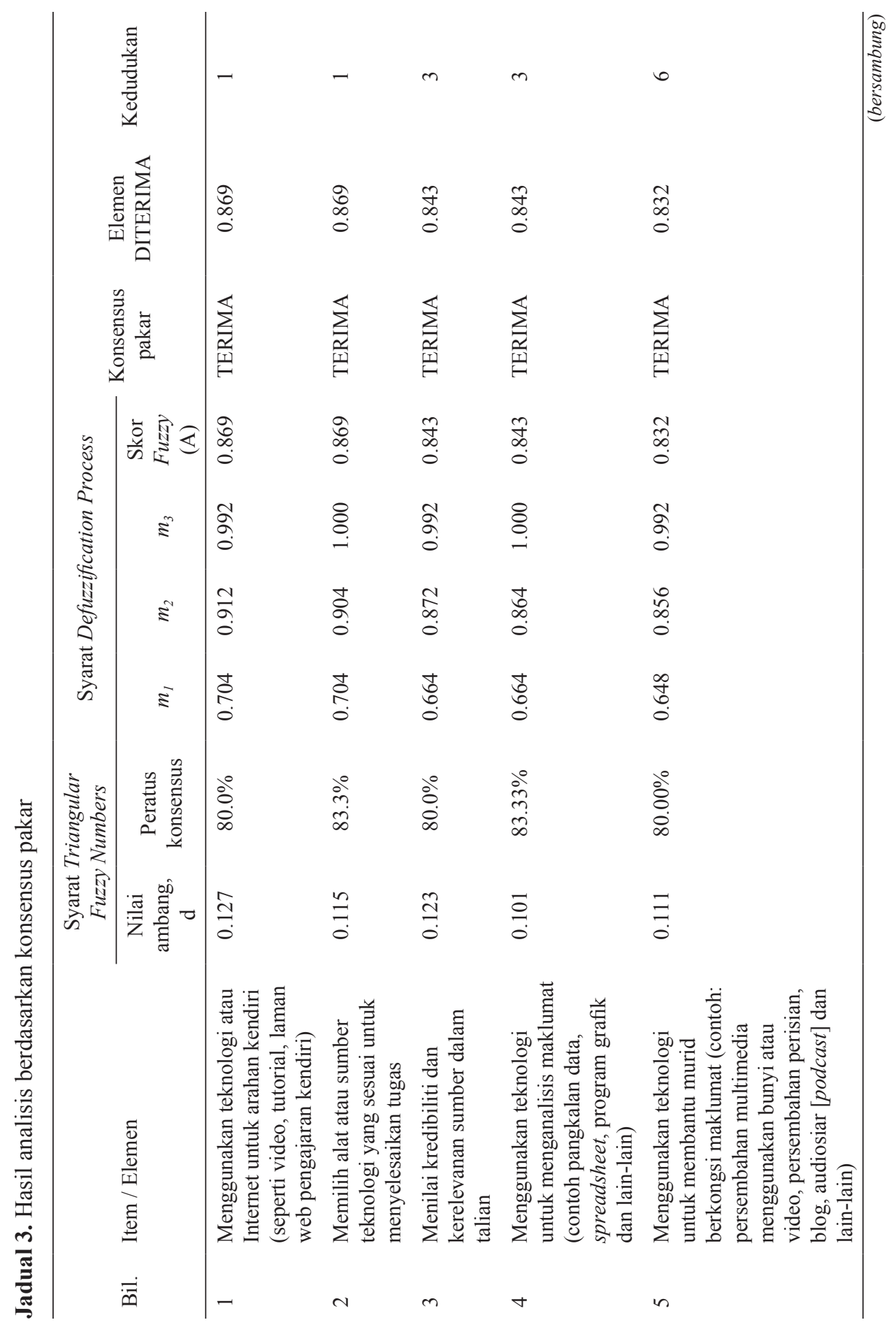


Aplikasi Teknik Fuzzy Delphi

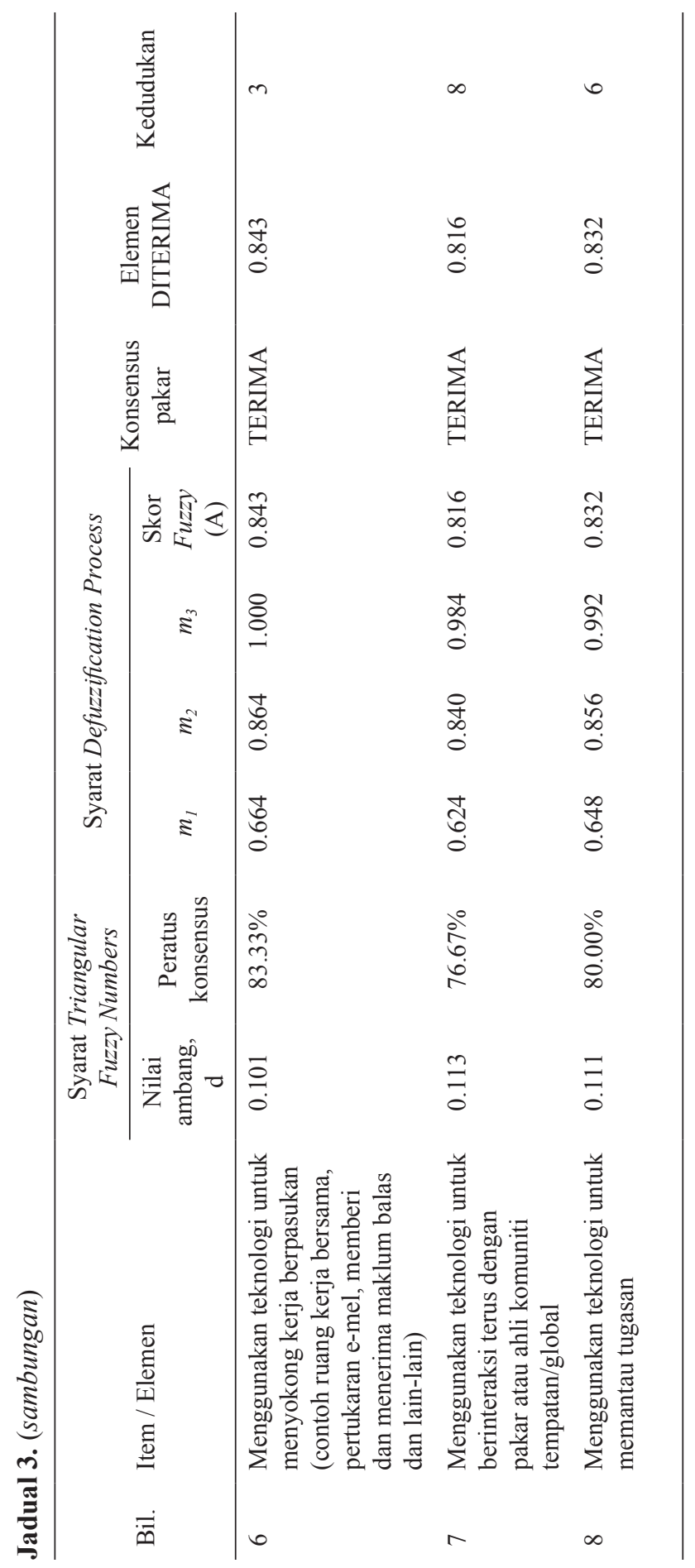


Kedudukan setiap elemen dapat dilihat berdasarkan nilai defuzzification pada Jadual 3. Justeru pengkaji melihat nilai skor defuzzification bagi elemen "menggunakan teknologi atau Internet untuk arahan kendiri (seperti video, tutorial, laman web pengajaran kendiri)" dan "memilih alat atau sumber teknologi yang sesuai untuk menyelesaikan tugas" berada di tangga pertama dengan nilai defuzzification sebanyak 0.869 . Seterusnya terdapat tiga elemen yang berada di tangga ketiga iaitu "menilai kredibiliti dan kerelevanan sumber dalam talian", "menggunakan teknologi untuk menganalisis maklumat (contoh pangkalan data, spreadsheet, program grafik dan lain-lain", dan "menggunakan teknologi untuk menyokong kerja berpasukan (contoh ruang kerja bersama, pertukaran e-mel, memberi dan menerima maklum balas dan lain-lain)" dengan nilai defuzzification sebanyak 0.843 . Elemen selanjutnya adalah elemen "menggunakan teknologi untuk membantu murid berkongsi maklumat (contoh persembahan multimedia menggunakan bunyi atau video, persembahan perisian, blog, podcast dan lainlain)" dan "menggunakan teknologi untuk memantau tugasan" dengan nilai defuzzification sebanyak 0.832. Akhir sekali elemen yang berada di tangga terakhir adalah "menggunakan teknologi untuk berinteraksi terus dengan pakar atau ahli komuniti tempatan atau global" iaitu sebanyak 0.816. Apabila kedudukan setiap elemen berada dalam susunannya maka dapatan kajian ini telah menjawab persoalan kajian kedua iaitu "berdasarkan pandangan pakar, apakah kedudukan elemen yang diperlukan dalam mengintegrasikan teknologi sebagai wadah dalam pembelajaran berasaskan pemikiran reka bentuk".

\section{PERBINCANGAN}

Daripada dapatan kajian terhadap analisis yang dijalankan, pengkaji dapat melihat kedudukan setiap elemen berdasarkan persetujuan yang diberikan oleh pakar. Kedudukan elemen adalah seperti berikut:

1. Menggunakan teknologi atau Internet untuk arahan kendiri (seperti video, tutorial, laman web pengajaran kendiri).

2. Memilih alat atau sumber teknologi yang sesuai untuk menyelesaikan tugas.

3. Menilai kredibiliti dan kerelevanan sumber dalam talian.

4. Menggunakan teknologi untuk menganalisis maklumat (contoh pangkalan data, spreadsheet, program grafik dan lain-lain).

5. Menggunakan teknologi untuk menyokong kerja berpasukan (contoh ruang kerja bersama, pertukaran e-mel, memberi dan menerima maklum balas dan lain-lain). 
6. Menggunakan teknologi untuk membantu murid berkongsi maklumat (contoh persembahan multimedia menggunakan bunyi atau video, persembahan perisian, blog, audiosiar [podcast] dan lain-lain).

7. Menggunakan teknologi untuk memantau tugasan.

8. Menggunakan teknologi untuk berinteraksi terus dengan pakar atau ahli komuniti tempatan/global.

Berdasarkan analisis skor defuzzification yang dijalankan, pengkaji melihat dua elemen yang mempunyai nilai skor defuzzification yang tinggi iaitu pertama; menggunakan teknologi atau Internet untuk arahan kendiri (seperti video, tutorial, laman web pengajaran kendiri) dan kedua; memilih alat atau sumber teknologi yang sesuai untuk menyelesaikan tugas. Pada pendapat pengkaji, ledakan teknologi maklumat menyebabkan guru kini berhadapan dengan murid yang terdiri daripada generasi $\mathrm{Y}$ dan $\mathrm{Z}$ yang rata-rata daripada mereka merupakan golongan yang celik digital. Kesannya, golongan ini mempunyai gaya pembelajaran yang lebih berorientasikan kendiri di mana murid bijak mengakses medium pembelajaran atas talian yang lebih menarik dan mudah difahami oleh mereka dan seterusnya membuat keputusan sendiri mengenai alat teknologi yang bersesuaian untuk menyelesaikan tugasan dengan baik. Dengan teknologi moden yang sentiasa berkembang, ternyata kemahiran yang diperlukan oleh murid pada abad ke-21 juga berbeza dengan generasi sebelumnya. Ini kerana bentuk pembelajaran murid abad ke-21 lebih berorientasikan kendiri dengan mengeksploitasi teknologi untuk melakukan projek dengan lebih efisien (Koh et al., 2015). Penggunaan teknologi memberi kelebihan kepada murid untuk bereksplorasi dan mencipta pengalaman baharu. Dapatan kajian ini menyokong teori konstruktivisme yang menggunakan pengetahuan sedia ada dan pengetahuan semasa untuk membuat hubung kait secara mendalam terhadap sesuatu pembelajaran(Dewey, 1916).

Elemen menilai kredibiliti dan kerelevanan sumber dalam talian berada di tempat ketiga. Elemen ini dilihat amat penting pada pandangan pakar kerana dalam era teknologi yang serba moden, maklumat dapat disampaikan dan dikongsi secara pantas. Maklumat ini diperoleh daripada pelbagai sumber yang tersedia di internet. Oleh itu pengkaji berpendapat penekanan strategi dan kemahiran mencari, mengumpul, menganalisis dan membuat penilaian maklumat dengan bijaksana adalah suatu kemahiran yang amat penting agar murid memperoleh maklumat bermakna yang sahih dan bersesuaian dengan konteks yang dingini. Elemen ini dilihat penting kerana setiap maklumat yang dipaparkan di dalam internet tidak semuanya betul dan murid perlu menilai kredibiliti dan kesahan maklumat yang diperoleh dalam talian sebelum digunakan sebagai rujukan (Baharuddin et al., 2003). 
Elemen menggunakan teknologi untuk menganalisis maklumat (contoh pangkalan data, spreadsheet, program grafik, dan lain-lain) turut berada di tempat ketiga. Kemahiran ini menjadikan aktiviti pembelajaran berasaskan pemikiran reka bentuk lebih berdaya saing dalam usaha meningkatkan penglibatan murid dalam kelas. Koh et al. (2015) mencadangkan supaya murid mempertimbangkan beberapa elemen seperti bahasa, grafik dan multimedia sebelum menganalisis sesuatu maklumat.

Elemen menggunakan teknologi untuk menyokong kerja berpasukan (contoh ruang kerja bersama, pertukaran e-mel, memberi dan menerima maklum balas, dan lain-lain) turut berkongsi tempat ketiga dengan dua elemen yang dinyatakan sebelum ini. Apabila berbicara tentang kerja berpasukan, aspek kolaborasi tidak boleh dikesampingkan. Dalam pemikiran reka bentuk apabila murid berinteraksi dengan rakan sebaya, mereka bukan sahaja mengamalkan kemahiran sosial yang dapat menyelesaikan konflik atau belajar bagaimana menghormati hak orang lain dan bagaimana cara untuk melindungi hak mereka sendiri tetapi juga memperoleh kemahiran teknikal yang canggih berkaitan dengan penyelesaian masalah, reka bentuk dan keputusan (Wells, 2012). Pada pendapat pengkaji, guru-guru perlu membimbing murid dalam menggunakan teknologi dengan memberi fokus kepada memupuk kemahiran, pengetahuan dan sikap murid bagi pembelajaran sepanjang hayat. Murid perlu diberi peluang untuk menggunakan teknologi dalam menyokong kerja berpasukan. Ini boleh dilakukan melalui pertukaran e-mel, perkongsian maklumat melalui Google Drive dan sebagainya.

Seterusnya elemen yang berada di tempat keenam adalah "menggunakan teknologi untuk membantu murid berkongsi maklumat (contoh persembahan multimedia menggunakan bunyi atau video, persembahan perisian, blog, podcast dan lainlain)". Elemen ini amat penting kerana bagi Doppelt (2007), sebab utama mengapa pembelajaran berasaskan pemikiran reka bentuk perlu diterapkan di sekolah adalah kerana murid perlu mengetahui bagaimana untuk membentangkan idea mereka kepada orang lain dan menerangkan proses yang terlibat. Ini disebabkan oleh murid yang mempunyai masalah membentangkan idea dalam tugasan yang dilakukan.(Berland et al., 2013).

Elemen "menggunakan teknologi untuk memantau tugasan" turut berada di tempat keenam. Kemahiran ini berkait dengan proses kognitif yang memberi peluang kepada murid membina sendiri platform yang bersesuaian untuk memantau tugasan dengan efektif. Penggunaan teknologi ini merupakan salah satu medium perkongsian untuk meningkatkan komunikasi dengan ahli kumpulan mahu pun dengan pemegang taruh dalam proses mereka bentuk (Koh et al., 2015). 
Akhir sekali elemen "menggunakan teknologi untuk berinteraksi terus dengan pakar atau ahli komuniti tempatan/global" berada di kedudukan terakhir. Dalam pembelajaran abad ke-21, kerjasama murid dengan pakar atau dengan ahli komuniti tempatan dan global sangat digalakkan. Ini secara langsung memberi peluang kepada murid bersuara dan membuat pilihan dengan penggunaan teknologi (Zhao, 2012). Elemen pengetahuan ini dapat menambahkan metakognisi murid serta sebagai satu medium perkongsian dengan pemegang taruh dan ahli kumpulan yang terlibat dalam proses mereka bentuk (Koh et al., 2015).

Oleh itu merujuk kepada penilaian pakar, teknologi memainkan peranan penting dalam corak pembelajaran berasaskan pemikiran reka bentuk. Ini kerana menurut Wells (2012), alat yang paling berkesan yang boleh disediakan dalam mengintegrasikan teknologi adalah keupayaan untuk berfikir secara kreatif seperti seorang pereka.

\section{RUMUSAN}

Kajian ini menunjukkan bahawa teknologi adalah wadah terpenting dalam pengintegrasian pembelajaran berasaskan pemikiran reka bentuk, khususnya teknologi yang boleh dieksploitasi secara efektif. Selain daripada itu, dua elemen yang berada di tangga ketiga dan keenam menunjukkan keperluan murid menguasai kemahiran teknologi peringkat pertengahan; menggunakan teknologi untuk menganalisis maklumat (contoh pangkalan data, spreadsheet, program grafik dan lain-lain); menggunakan teknologi untuk membantu murid berkongsi maklumat (contoh persembahan multimedia menggunakan bunyi atau video, persembahan perisian, blog, audiosiar dan lain-lain), sementara guru sebagai fasilitator membimbing murid untuk mengaplikasikan teknologi pembelajaran yang lebih kompleks dalam pembelajaran berasaskan pemikiran reka bentuk. Justeru guru sewajarnya memupuk kemahiran teknologi murid dengan menambahkan lagi keberkesanan pembelajaran berasaskan pemikiran reka bentuk melalui interaksi yang intensif bagi merangsang penglibatan murid menggunakan teknologi. Ini kerana murid yang lemah dalam pembelajaran kontemporari tidak dapat bersaing dalam pembelajaran digital kerana tidak mampu menguasai kemahiran asas dan teknologi demi untuk menguruskan dunia hari ini (Claro et al., 2012). Oleh itu adalah penting kurikulum sekolah menyediakan murid dengan kemahiran yang membolehkan mereka menggunakan teknologi secara lazim dan dasar pendidikan perlu membangunkan tindakan untuk mengurangkan jurang baru ini dalam pembelajaran murid. Dengan itu, elemen-elemen yang disediakan dalam kajian ini dapat digunakan dengan baik sebagai garis panduan kepada guru-guru 
menggunakan aspek teknologi dalam pendidikan terutamanya pembelajaran berasaskan pemikiran reka bentuk.

Kajian ini mempunyai beberapa batasan. Pertama, kajian ini memberi panduan kepada guru-guru bagaimana teknologi boleh digunakan dalam pembelajaran berasaskan pemikiran reka bentuk untuk murid sekolah rendah. Hasil dapatan akan berbeza jika kajian ini disasarkan kepada murid sekolah menengah, mahu pun pelajar universiti yang lebih berpengalaman dalam penggunaan teknologi. Kedua, jumlah responden yang mengambil bahagian adalah kecil. Justeru disarankan kajian lanjutan dilakukan dengan mengulangi kajian ini dengan menggunakan responden kajian yang lebih banyak yang dapat menentukan sejauh mana dapatan ini dapat digeneralisasikan. Akhir sekali, kajian ini adalah terhad kepada pembelajaran berasaskan pemikiran reka bentuk sahaja. Oleh itu kajian lanjutan diperlukan untuk mengkaji pembelajaran lain yang menggunakan konteks teknologi yang sama.

\section{RUJUKAN}

Adler, M., \& Ziglio, E. (1996). Gazing into the oracle: The Delphi method and its application to social policy and public health. London: Jessica Kingsley Publishers.

Baharuddin Aris, Mohamad Bilal Ali, Norah Md. Noor, Mohd. Nihra Haruzuan Muhammad Said, Noor Azean Atan, Manimegalai Subramaniam, \& Zaleha Abdullah. (2003). Sains Komputer: Teknik dan teknologi. Selangor: Venton Publishing (M) Sdn Bhd.

Berland, L. K., Martin, T. H., Ko, P., Peacock, S. B., Rudolph, J. J., \& Golubski, C. (2013). Student learning in challenge-based engineering curricula. Journal of Pre-College Engineering Education Research (J-PEER), 3(1), 5.

Bodjanova, S. (2006). Median alpha-levels of a fuzzy number. Fuzzy Sets and Systems, 157, 879-891. https://doi.org/10.1016/j.fss.2005.10.015

Boss, S. (2012). Bringing innovation to school: Empowering students to thrive in a changing world. London: Solution Tree Press.

Brown, T. (2008). Design thinking. Harvard Business Review, June, 84-92.

Buchanan, B. G. (2001). Creativity at the metalevel: AAAI-2000 presidential address, $A I$ Magazine, 22(3), 13. https://doi.org/10.1609/aimag.v22i3.1569

Chai, C. S., Deng, F., Tsai, P-S. Koh, J. H. L., \& Tsai, C-C. (2015). Assessing multidimensional students' perceptions of twenty-first-century learning practices. Asia Pacific Education Review, 16(3), 389-398. https://doi.org/10.1007/s12564015-9379-4

Chang, P. T., Huang, L. C., \& Lin, H. J. (2000). The fuzzy Delphi method via fuzzy statistics and membership function fitting and an application to the human resources. Fuzzy Sets and Systems, 112, 511-520. https://doi.org/10.1016/S0165-0114(98)00067-0 
Chen, C.-T. (2000). Extensions of the topsis for group decision-making under fuzzy environment. Fuzzy Sets and Systems, 114(1), 1-9. https://doi.org/10.1016/ S0165-0114(97)00377-1

Cheng, C.-H., \& Lin, Y. (2002). O.R. applications: Evaluating the best main battle tank using fuzzy decision theory with linguistic criteria evaluation. European Journal of Operational Research, 142, 174-186. https://doi.org/10.1016/S03772217(01)00280-6

Chu, H.-C., \& Hwang, G.-J. (2008). A delphi-based approach to developing expert systems with the cooperation of multiple experts. Expert Systems With Applications, 34, 2826-2840. https://doi.org/10.1016/j.eswa.2007.05.034

Claro, M., Preiss, D. D., San Martín, E., Jara, I., Hinostroza, J. E., Valenzuela, S., ..., \& Nussbaum, M. (2012). Assessment of 21st century ICT skills in Chile: Test design and results from high school level students. Computers \& Education, 59(3), 1042-1053. https://doi.org/10.1016/j.compedu.2012.04.004

Collins, A., \& Halverson, R. (2009). Rethinking education in the age of technology: The digital revolution and schooling in America. New York: Teachers College Press.

Crane, C. M. (2005). Teacher perceived impact of technology on elementary classrooms and teaching. Unpublished doctoral dissertation, Universiti of Missouri. http:// search.proquest.com/docview/305456189?accountid=6444 https://doi.org/10.32 469/10355/4192

Dewey, J. (1916). Democracy and education. New York, NY: Macmillan.

Dewey, J., \& Dewey, E. (1915). Schools of To-morrow. New York: E. P. Dutton.

Doppelt, Y. (2007). Assessing creative thinking in design-based learning. International Journal of Technology and Design Education, 19(1), 55. https://doi.org/10.1007/ s10798-006-9008-y

Dougherty, L. A. (2015). Stratosphere: Integrating technology, pedagogy, and change knowledge. Contemporary Educational Technology, 6(2), 169-171.

Greene, J. A., Yu, S. B., \& Copeland, D. Z. (2014). Measuring critical components of digital literacy and their relationships with learning. Computers \& Education, 76(Supplement C), 55-69. https://doi.org/10.1016/j.compedu.2014.03.008

Hartley, A. J. (2014). A mixed methods study exploring the perceived barriers to technology integration among elementary teachers in four elementary schools within a northern Genesee county school district. Retrieved 20 February 2018 from, http:// search.proquest.eom/doeview/1 705809219?accountid=6444

Hixson, N. K., Ravitz, J., \& Whisman, A. (2012). Extended professional development in project-based learning: Impacts on 21st century skills teaching and student achievement. Charleston, West Virginia: West Virginia Department of Education.

Jayabalan, L. (2009). Tabiat mencari maklumat menerusi internet dalam kalangan guru sekolah menengah di daerah Kluang. Masters thesis, Universiti Teknologi Malaysia.

Jones, H., \& Twiss, B. C. (1978). Forecasting technology for planning decisions. London: Macmillan.

Kelley, D. \& Van Patter, G. K. (2005). Design as glue: Understanding the Stanford D. School. NextD Journal Conversation, 21, 1-9. 
Kirschner, P. (2015). Do we need teachers as designers of technology enhanced learning? Instructional Science, 43(2), 309-322. https://doi.org/10.1007/s11251015-9346-9

Koehler, M. J., \& Mishra, P. (2005). What happens when teachers design educational technology? The development of Technological Pedagogical Content Knowledge. Journal of Educational Computing Research, 32(2), 131-152. https://doi. org/10.2190/0EW7-01WB-BKHL-QDYV

Koh, J. H. L., Chai, C. S., Wong, B., \& Hong, H.-Y. (2015). Design thinking and education. In Koh, J. H. L., Chai, C. S., Wong, B., \& Hong, H.-Y. (Eds.). Design thinking for education: Conceptions and applications in teaching and learning (pp. 1-15). Singapore: Springer.

Marlowe, B. A., \& Page, M. L. (1998). Creating and sustaining the constructivist classroom. Thousand Oaks, CA: Corwin Press.

Mishra, P., \& Koehler, M. J. (2006). Technological pedagogical content knowledge: A framework for teacher knowledge. Teachers College Record, 108(6), 1017-1054. https://doi.org/10.1111/j.1467-9620.2006.00684.x

Mohd Ridhuan Mohd Jamil, Saedah Siraj, Zaharah Hussin, Nurulrabihah Mat Noh, \& Ahmad Ariffin Sapar. (2017). Pengenalan asas kaedah fuzzy delphi dalam penyelidikan reka bentuk dan pembangunan. Bangi, Selangor: Minda Intelek Agency.

Murry, J. W., \& Hammons, J. O. (2017). Delphi: A versatile methodology for conducting qualitative research. The Review of Higher Education, 18(4), 423-436. https:// doi.org/10.1353/rhe.1995.0008

Norton, P., \& Hathaway, D. (2015). In search of a teacher education curriculum: Appropriating a design lens to solve problems of practice. Educational Technology, 55(6), 3-14.

Ocampo, L., Ebisa, J. A., Ombe, J., \& Geen Escoto, M. (2018). Sustainable ecotourism indicators with fuzzy Delphi method: A Philippine perspective. Ecological Indicators, 93, 874-888. https://doi.org/10.1016/j.ecolind.2018.05.060

Pill, J. (1971). The Delphi method: Substance, context, a critique and an annotated bibliography. Socio-Economic Planning Sciences, 5(1), 57-71. https://doi. org/10.1016/0038-0121(71)90041-3

Prensky, M. (2010). Teaching digital natives: Partnering for real learning. Thousand Oaks, CA: Corwin Press.

Robinson, K. (2011). Out of our minds: Learning to be creative. Hoboken, NJ: Capstone.

Saaty, T. L., \& Özdemir, M. S. (2014). How many judges should there be in a group? Annals of Data Science, 1(3), 359-368. https://doi.org/10.1007/s40745-0140026-4

Sara Jolly, J. (2017). Technology in the montessori classroom: Teachers' beliefs and technology use. Journal of Montessori Research, 3(1), 16-29. https://doi. org/10.17161/jomr.v3i1.6458

Taboada, M. B., \& Coombs, G. (2013). Liminal moments: Designing, thinking and learning. Paper presented at the Design Learning for Tomorrow-Design Education from Kindergarten to $\mathrm{PhD}$, Oslo, Norway, 14-17 May. 
Tang, C.-W., \& Wu, C.-T. (2010). Obtaining a picture of undergraduate education quality: A voice from inside the university. Higher Education, 60(3), 269-286. https:// doi.org/10.1007/s10734-009-9299-5

Trilling, B., \& Fadel, C. (2009). 21st century skills: Learning for life in our times. San Francisco: CA: John Wiley \& Sons,.

Wells, A. (2012). The importance of design thinking for technological literacy: A phenomenological perspective. International Journal of Technology and Design Education, 23(3), 623-636. https://doi.org/10.1007/s10798-012-9207-7

Zhao, Y. (2012). World class learners: Educating creative and entrepreneurial students. Thousand Oaks, CA: Corwin Press (A Joint Publication with the National Association of Elementary School Principals). 